\title{
Fibrosis in the kidney: is a problem shared a problem halved?
}

\author{
Tim D Hewitson \\ From Fibroproliferative disorders: from biochemical analysis to targeted therapies \\ Frauenchiemsee, Germany. 25-30 September 2010
}

\begin{abstract}
Fibrotic disorders are commonplace, take many forms and can be life-threatening. No better example of this exists than the progressive fibrosis that accompanies all chronic renal disease. Renal fibrosis is a direct consequence of the kidney's limited capacity to regenerate after injury. Renal scarring results in a progressive loss of renal function, ultimately leading to end-stage renal failure and a requirement for dialysis or kidney transplantation.

Although it manifests itself histologically as an increase in extracellular matrix, we know that the histological appearance can be caused by a de novo synthesis of matrix (primarily collagen), or a disproportionate loss of renal parenchyma. In both cases the process depends on a resident mesenchymal cell, the so-called myofibroblast, and is independent of disease etiology. Potentially we can ameliorate fibrosis, either indirectly by modifying the environment the kidney functions in, or more directly by interfering with activation and function of myofibroblasts. However, while renal fibrosis shares many features in common with the wound healing response in other organs, we also recognise that the consequences can be highly kidney specific. This review highlights the similarities and differences between this process in the kidney and other organs, and considers the therapeutic implications.
\end{abstract}

\section{Introduction}

Fibrosis involves an excess accumulation of extracellular matrix (primarily composed of collagen) and usually results in loss of function when normal tissue is replaced with scar tissue [1]. No better example of this exists than the progressive fibrosis that accompanies all chronic renal disease. However, an overview of renal disease suggests that complementary but different mechanisms are responsible for fibrosis. Likewise, although there are obvious parallels between fibrosis in the kidney and elsewhere, there are also a number of important differences, and kidney specific consequences, that distinguish progressive renal disease. The purpose of this review is to summarise the mechanisms of renal fibrosis and its causes and consequences. In doing so it will emphasise the similarities and differences between the renal response and that of other organs.

Correspondence: tim.hewitson@mh.org.au

Department of Nephrology, Royal Melbourne Hospital \& Department of Medicine, University of Melbourne, Melbourne, Australia

\section{Discussion}

Etiology of renal disease

Kidney disease consists of a diverse range of etiologies, including immunological, mechanical, metabolic and toxic insults amongst others. These variously affect the three functional compartments of the kidney; the vasculature, glomerulus and tubulointerstitium. It is these compartments that are collectively responsible for the delivery of blood, plasma filtration and modification of the glomerular filtrate respectively. Regardless of etiology, all patients with chronic kidney disease show a decline in renal function with time [2]. The process is irreversible, inevitably leading to end-stage renal failure, a condition that requires lifelong dialysis or renal transplantation. Histologically endstage kidney disease manifests itself as fibrotic lesions affecting each compartment; glomerulosclerosis, vascular sclerosis and tubulointerstitial fibrosis (Figure 1). Even though matrix synthesis is of course part of the normal repair process that occurs after injury, excessive synthesis of extracellular matrix is itself destructive, further exacerbating injury in a vicious cycle.
C Biomed Central

C 2012 Hewitson; licensee BioMed Central Ltd. This is an Open Access article distributed under the terms of the Creative Commons Attribution License (http://creativecommons.org/licenses/by/2.0), which permits unrestricted use, distribution, and reproduction in any medium, provided the original work is properly cited. 


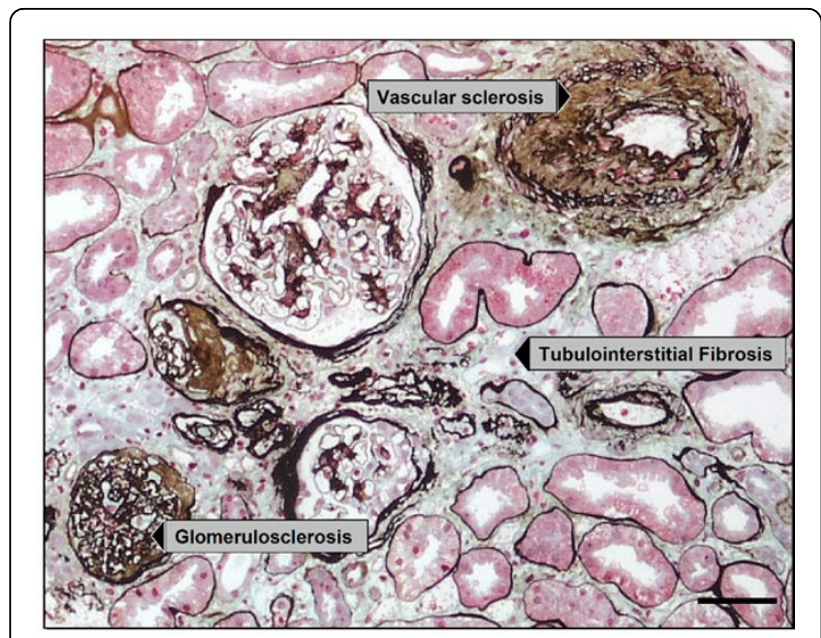

Figure 1 Histology of end-stage kidney disease consists of tubulointerstitial fibrosis (middle), glomerulosclerosis (bottom left) and vascular sclerosis (top right). Silver methenamine/Masson trichrome stain. Scale bar $=50 \mu \mathrm{m}$.

\section{How does fibrosis develop?}

We perhaps most commonly associate scarring with an excess synthesis of matrix, usually collagen. Keloids for instance represent a quintessential example of scarring which results from aberrant matrix synthesis. Nevertheless, although keloids are an extreme case, mechanistically similar processes occur in deep organ fibrosis. There are certainly renal parallels of this process, such as the focal scarring that accompanies a localised tissue trauma.

What does however now seem clear, is that aberrant matrix synthesis is only part of the process [3]. Temporal studies in experimental renal infection indicate that aberrant collagen synthesis is often transient, peaking in the first few days after infection. Histologically however, scarring as defined by increasing matrix density, continues to increase [4].

How can we account for this discrepancy? Although it has long been known that end-stage kidneys are smaller than their unscarred counterparts, it is the focal lesions found in diseases such as reflux nephropathy that provide us with a clue. The irregular surface of these kidneys indicates underlying scar tissue, highlighting the fibro-contractive nature of renal scarring. Once again, there are established non-renal examples of this process. Wound contraction has long been recognised as an integral part of skin wound healing, with the drawing together of wound edges an important part of wound closure [5]. Direct renal evidence comes from examining the histology in experimental renal infection and scarring. Being a primary tubulointerstitial model of injury, the glomeruli are largely unaffected during fibrosis, the density of glomeruli therefore providing a measure of parenchymal collapse. In what we term the "balloon" hypothesis [3], fibrosis is therefore due not only to an increase in matrix synthesis but also to the collapse of the renal parenchyma. Analogous to deflating a balloon, we are effectively measuring the same amount of matrix in a smaller volume. Morphometric studies in this model show that the combined effect of an acute increase in collagen expression and a later collapse of the renal parenchyma account for the progressive increase in scar tissue [4].

\section{What is the cellular basis of this process?}

Fibrosis in all three anatomical compartments is associated with the activities of a mesenchyme derived cell. The interstitial fibroblast, glomerular mesangial cell and vascular smooth muscle cell are phenotypically similar, with the fibroblast and mesangial cell acquiring features of smooth muscle when activated [5-7].

In each compartment the resident mesenchymal cell is not only the principal extracellular matrix producing cell, but is also the force for contraction and reorganisation of extracellular matrix, thereby increasing its density [5].

The renal interstitial fibroblast is typical of all three scenarios and has been the focus of our studies of tubulointerstitial fibrosis. Recognised by its de novo synthesis of $\alpha$ smooth muscle actin ( $\alpha \mathrm{SMA})$, activated fibroblasts, socalled myofibroblasts, are a feature of all forms of progressive renal disease where their accumulation is strongly associated with disease progression [5,7]. Myofibroblasts are probably derived from multiple sources, including not only resident fibroblasts, but also pericytes, blood borne precursors and transition of adjacent epithelial cells and endothelial cells, the relative importance of each being the subject of much conjecture [8].

Regardless, myofibroblasts proliferate locally, synthesise the extracellular matrix components that constitute interstitial fibrosis and contract and reorganise matrix to increase its density. Epigenetic modifications lead to persistent activation of the protooncogene Ras, perpetual fibroblast proliferation and fibrogenesis [9]. These changes are stable modifications that can be inherited through multiple cell divisions. In what is a vicious cycle, interstitial fibrosis is probably a cause of mechanical injury and through a reduction in vascularization, increases hypoxia [10].

\section{Pro-fibrotic influences}

Interstitial fibroblast function and differentiation is regulated by a plethora of factors, with a variety of molecules shown to directly influence renal mesenchymal cells in vitro [5]. Differentiation of myofibroblasts, proliferation and collagen synthesis are stimulated by a variety of cytokines and growth factors derived from adjacent stimulated tubular epithelial cells, endothelial cells, leukocytes or from fibroblast themselves. Other influences include mechanical forces and extracellular matrix itself. 
A hierarchy exists amongst the profibrotic growth factors, with the most compelling evidence being for transforming growth factor $\beta 1$ (TGF $\beta 1$ ) and platelet derived growth factor (PDGF). Where kidney injury is persistent or repeated, increasing numbers of injured epithelial cells stall between the $G 2$ and $M$ phases of the cell cycle, which results in an ongoing production of TGF $\beta 1$ [11]. It is also likely that fibroblasts are stimulated more directly in some diseases because high glucose concentrations [12] and angiotensin II [13] stimulate in vitro renal cortical fibroblast proliferation and collagen production.

Likewise the contraction of renal parenchyma is under cytokine control. Most of what we know about collagen reorganisation comes from in vitro studies of collagen gel contraction and reorganisation. In a process that is directly proportional to the number of cells present, fibroblasts embedded in solidified collagen progressively contract matrix to reduce gel diameter and increase matrix density. We know that this process is dependent upon $\beta 1$ integrins found on the surface of renal fibroblasts. Blocking these receptors with specific antisera is sufficient to abrogate fibroblasts binding to collagen $\mathrm{I}$, and in doing so abrogate gel contraction [14]. Again however, the process is complex and is due both to contraction in the surrounding matrix, in the same way as a sea anemone retracts its tentacles, and traction or migration of fibroblasts through surrounding matrix, akin to the movement of a spider through its web, pulling on the filaments.

\section{Endogenous anti-fibrotic factors}

As our understanding of myofibroblast function has increased, we have come to appreciate that the actions of pro-fibrotic factors are counteracted by the activities of endogenous reno-protective agents [15]. Theoretically at least it is the balance of these opposing factors that determine progression [16]. Several have been characterised including hepatocyte growth factor [17], bone morphogenic protein-7 [18] and the hormone relaxin $[19,20]$.

\section{A common pathway?}

Clearly, as outlined above, renal fibrosis can result from different mechanisms - both excess matrix synthesis and contraction independently and collectively contribute. In many respects this parallels fibrosis in other organs. Kidney fibrosis, as elsewhere, is dependent upon the recruitment of a myofibroblast-like cell. The process is both fibro-proliferative, fibrogenic and fibro-contractive, and is under the influence of both pro-fibrotic factors released during injury, and endogenous reno-protective factors.

However, there are a number of differences between the kidney and other organs which impact on the in vivo consequences of injury (Table 1).
Firstly, and perhaps most importantly, is the inherent complexity of the kidney. The kidney consists of more than 20 different cell types. Not only does this exacerbate the in situ consequences of injury but it also affects the ability of the kidney to regenerate after an insult. The clinical reality is that the delicate structure of the glomerulus is particularly prone to damage, with very limited, if any, capacity to regenerate.

Much renal disease is associated with breakdown of the glomerular filtration barrier, and passage of excess protein. Proteinuria is toxic, excess downstream tubular reabsorption of protein results in tubular inflammation and fibrosis. Patients who develop progressive renal failure also retain solutes normally excreted by the healthy kidney. The circulating uraemic serum consists of a complex mixture of more that 50 known or putative toxins [21]; including small water bound solutes, middle molecules and protein bound molecules [22]. The influence of these toxins on renal cell function is well recognised [21], with direct evidence to show that uraemia is a permissive factor in the pathogenesis of fibrosis systemically [23].

While the kidney is well vascularised, the high oxygen consumption of tubules [24] makes them highly susceptible to any reduction in interstitial oxygen supply or delivery. It has for instance long been known that the kidney accounts for almost $25 \%$ of the body's resting oxygen consumption [25]. Oxygen deprivation is sensed through a refined molecular system whose activation has been shown to initiate renal fibrosis in animal models [10,26]. Hypoxia is also probably both a consequence and cause of further progression [10].

Finally, but not least of all, is the role of arterial pressure dependent factors. Activation of the renin-angiotensin-aldosterone system (RAAS) is pivotal to the pathogenesis of much renal disease [27], and accounts in part for the close relationship between renal disease and cardiovascular complications. Effects on fibrosis may be both indirect (hypertension and mechanical injury) and direct (angiotensin II mediated fibrogenesis and contraction).

\section{Therapeutic implications}

Organ specific differences have therapeutic implications. Renal specific factors result in renal specific treatment strategies. For instance control of blood pressure and angiotensin II are the most proven ways of preventing progression [28] and secondary fibrosis in the kidney [29]. They however have limited application outside the reno-cardio vascular system, where hypotension prevails. Likewise protein restriction can ameliorate the toxic effects of proteinuria [30]. The challenge is therefore to find those generic anti-fibrotic strategies that have potential to ameliorate progression in multiple organs, that is, the overlap. Inhibition of the profibrotic factors, use of 
Table 1 Renal specific factors contributing to kidney fibrosis

\begin{tabular}{lll}
\hline & Factor & Cause \\
\hline 2 & Complexity & Kidney consists of $\sim 20$ different cell types \\
\hline 3 & Poor capacity for regeneration & $\begin{array}{l}\text { Damaged glomeruli do not regenerate } \\
\text { Each nephron is anatomically distinct }\end{array}$ \\
& Toxins & $\begin{array}{l}\text { Protein leakage and tubule uptake } \\
\text { Uraemic milieu ( }>50 \text { putative or proven toxins) }\end{array}$ \\
\hline 4 & Uraemia & \\
\hline 5 & Hypoxia & High tubule demand for oxygen \\
\hline
\end{tabular}

endogenous renoprotective factors and deletion of fibroblasts are all promising targets.

\section{Conclusion}

In conclusion, many chronic diseases progress by fibrosis, amelioration of which can play an important role in patient management. Clinical nephrology in particular is inexorably linked to the histology of the renal biopsy . As we learn more about the histology and mechanisms of fibrosis, studies in both the kidney and elsewhere will continue to identify potential organ specific and generic therapeutic targets.

\section{Acknowledgements}

This article has been published as part of Fibrogenesis \& Tissue Repair Volume 5 Supplement 1, 2012: Proceedings of Fibroproliferative disorders: from biochemical analysis to targeted therapies. The full contents of the supplement are available online at http://www.fibrogenesis.com/ supplements/5/S1

TDH is supported by project grant funding (628634 and 1004235) from the National Health and Medical Research Council of Australia.

\section{Competing interests}

The author declares that they have no competing interests.

Published: 6 June 2012

\section{References}

1. Wynn TA: Common and unique mechanisms regulate fibrosis in various fibroproliferative diseases. J Clin Invest 2007, 117:524-529.

2. Hakim RM, Lazarus JM: Progression of chronic renal failure. Am J Kidney Dis 1989, 14:396-401.

3. Hewitson TD: Renal tubulointerstitial fibrosis: common but never simple. Am J Physiol Renal Physiol 2009, 296:F1239-F1244.

4. Hewitson TD, Darby IA, Bisucci T, Jones CL, Becker GJ: Evolution of tubulointerstitial fibrosis in experimental renal infection and scarring. J Am Soc Nephrol 1998, 9:632-642.

5. Darby IA, Hewitson TD: Fibroblast differentiation in wound healing and fibrosis. Int Rev Cytol 2007, 257:143-179.

6. Alpers CE, Hudkins KL, Gown AM, Johnson RJ: Enhanced expression of "muscle-specific" actin in glomerulonephritis. Kidney Int 1992, 41:1134-1142.

7. Hewitson TD, Becker GJ: Interstitial myofibroblasts in IgA glomerulonephritis. Am J Nephrol 1995, 15:111-117.

8. Quaggin SE, Kapus A: Scar wars: mapping the fate of epithelialmesenchymal-myofibroblast transition. Kidney Int 2011, 80:41-50

9. Bechtel W, McGoohan S, Zeisberg EM, Muller GA, Kalbacher H, Salant DJ, Muller CA, Kalluri R, Zeisberg M: Methylation determines fibroblast activation and fibrogenesis in the kidney. Nat Med 2010, 16:544-550.
10. Tanaka T, Nangaku M: The role of hypoxia, increased oxygen consumption, and hypoxia-inducible factor- 1 alpha in progression of chronic kidney disease. Curr Opin Nephrol Hypertens 2010, 19:43-50.

11. Yang L, Besschetnova TY, Brooks CR, Shah JV, Bonventre JV: Epithelial cell cycle arrest in G2/M mediates kidney fibrosis after injury. Nat Med 2010 16:535-43, 1p.

12. Lam S, Verhagen NAM, Strutz F, Van Der Pijl JW, Daha MR, Van Kooten C: Glucose-induced fibronectin and collagen type III expression in renal fibroblasts can occur independent of TGF-beta1. Kidney Int 2003, 63:878-888.

13. Ruiz-Ortega M, Egido J: Angiotensin II modulates cell growth-related events and synthesis of matrix proteins in renal interstitial fibroblasts. Kidney Int 1997, 52:1497-1510.

14. Kelynack KJ, Hewitson TD, Nicholls KM, Darby IA, Becker GJ: Human renal fibroblast contraction of collagen I lattices is an integrin mediated process. Nephrol Dial Transplant 2000, 15:1766-1772.

15. Eddy AA: Progression in chronic kidney disease. Adv Chronic Kidney Dis 2005, 12:353-365.

16. Liu Y: Renal fibrosis: New insights into the pathogenesis and therapeutics. Kidney Int 2006, 69:213-217.

17. Liu Y: Hepatocyte growth factor in kidney fibrosis: therapeutic potentia and mechanisms of action. Am J Physiol Renal Physiol 2004, 287:F7-16.

18. Zeisberg M, Muller GA, Kalluri R: Are there endogenous molecules that protect kidneys from injury? The case for bone morphogenic protein-7 (BMP-7). Nephrol Dial Transplant 2004, 19:759-761.

19. Garber SL, Mirochnik Y, Brecklin CS, Unemori EN, Singh AK, Slobodskoy L, Grove $B H$, Arruda JAL, Dunea G: Relaxin decreases renal interstitial fibrosis and slows progression of renal disease. Kidney Int 2001, 59:876-882.

20. Samuel CS, Hewitson TD: Relaxin and the progression of kidney disease. Curr Opin Nephrol Hypertens 2009, 18:9-14.

21. Horl WH: Uremic toxins: new aspects. J Nephrol 2000, 13(Suppl 3):S83-S88.

22. Vanholder R, Glorieux $G$, Lameire N: Uraemic toxins and cardiovascular disease. Nephrol Dial Transplant 2003, 18:463-466.

23. Wessles S, Amann K, Tornig J, Ritz E: Cardiovascular structural changes in uremia: Implications for cardiovascular function. Semin Dial 1999, 12:288-292.

24. Lewy PR, Quintanilla A, Levin NW, Kessler RH: Renal energy metabolism and sodium reabsorption. Annu Rev Med 1973, 24:365-384.

25. In Geigy Scientific Tables.. 8 edition. Basle: Ciba-Geigy;Lentner C 1984:

26. Kimura K, Iwano M, Higgins DF, Yamaguchi Y, Nakatani K, Harada K, Kubo A Akai Y, Rankin EB, Neilson EG, et al: Stable expression of HIF-1alpha in tubular epithelial cells promotes interstitial fibrosis. Am J Physiol Renal Physiol 2008, 295:F1023-F1029.

27. Ruster C, Wolf G: Renin-Angiotensin-Aldosterone System and Progression of Renal Disease. J Am Soc Nephrol 2006, 17:2985-2991.

28. Lewis EJ, Hunsicker LG, Clarke WR, Berl T, Pohl MA, Lewis JB, Ritz E, Atkins RC, Rohde R, Raz I: Renoprotective effect of the angiotensinreceptor antagonist irbesartan in patients with nephropathy due to type 2 diabetes. $N$ Eng J Med 2001, 345:851-860.

29. Ishidoya S, Morrissey J, McCracken R, Reyes A, Klahr S: Angiotensin II receptor antagonist ameliorates renal tubulointerstitial fibrosis caused by unilateral ureteral obstruction. Kidney Int 1995, 47:1285-1294.

30. Ihle BU, Becker GJ, Whitworth JA, Charlwood RA, Kincaid-Smith PS: The effect of protein restriction on the progression of renal insufficiency. $N$ Engl J Med 1989, 321:1773-1777. 
doi:10.1186/1755-1536-5-S1-S14

Cite this article as: Hewitson: Fibrosis in the kidney: is a problem

shared a problem halved? Fibrogenesis \& Tissue Repair 2012 5(Suppl 1):S14.

Submit your next manuscript to BioMed Central and take full advantage of:

- Convenient online submission

- Thorough peer review

- No space constraints or color figure charges

- Immediate publication on acceptance

- Inclusion in PubMed, CAS, Scopus and Google Scholar

- Research which is freely available for redistribution

Submit your manuscript at 